live clinical situations, here students can refer back to the video material as often as needed.

(3) Follow-up language practice

This includes some or all of the following:

(a) taking history notes from a videotaped interview (formal-written)

(b) giving an account of a case for newspaper publication (informal-written)

(c) the same, for presentation at a clinical conference (formal-spoken)

(d) Class discussion of treatment (semi-formalspoken)

(e) Role play explanation of treatment to a patient (quasi informal-spoken).

(4) Further developments of the course

As students' one-to-one skills become more polished, interactional ability can be addressed. This includes holding and gaining attention in groups such as clinical conferences. Such behaviour is in part culturally determined and both speech and body language have a function.

Example: There are many ways of interrupting a speaker who is holding the floor, some requiring prior exaggerated agreement or apology as well as certain body movements:

A: So I feel that we should discharge this patient ..

B: (leans forward, attempts to catch A's eye): Could I just say ...

A: $\ldots$ under the supervision of a community nurse...

B: (raises finger, shifts position in chair): I'm sorry to interrupt ...
A: $\quad$. although I realise that not everyone may agree ...

B: (nods with increasing vigour): Yes . . . I take your point but ...

And so $B$ gains the floor and is able to disagree

\section{Course results}

Assessment is continuous without formal testing. Objectively students are seen to gain in fluency, competence and accuracy. They themselves report improvement in both confidence and subjective competence.

When the course ends, the students begin working directly with patients in whom they must assess subjective mood, suicidal intent, family discord, ambivalent attitudes, speech disorder and delusions, all in a foreign language. For this intimidating task the course offers a foundation in the real use of English across a variety of clinical situations, accents and dialects. In doing so it should also allow effective learning, good patient care and exam success.

\section{References}

ApPleby, L. \& ARAYA, R. (1990) Postgraduate training in psychiatry 1977-1987: Disturbing trends in the pattern of international cooperation. Medical Education, 24, 290-297.

CAWLEY, R. H. (1986) Overseas graduates and the MRCPsych. Bulletin of the Royal College of Psychiatrists, 10, 60-63.

Hollander, D., Appleby, L. \& CheCkley, S. (1989) Mental health education for primary health care. Psychiatric Bulletin, 13, 73-76.

\title{
Achieving Resource Management
}

A national exhibition and conference will be held on 30 November 1990 in the New Connaught Rooms, Great Queen Street, London. This event is supported by the Department of Health and it will gather together virtually all the major hardware and software systems used in support of resource man- agement and medical audit. Further information: Jane Statham, Conference Manager, Mercia Publications Ltd., The Science Park, University of Keele, Keele, Staffordshire ST5 5SP (telephone 0782 625056; fax 0782 717732). 